\title{
MORPHOMETRIC STUDY OF LUMBAR VERTEBRAE IN CENTRAL INDIAN POPULATION AND ITS CLINICAL IMPORTANCE
}

\author{
Sonali Agichani', S. D. Joshi², S. S. Joshi ${ }^{3}$
}

${ }_{1}^{1}$ Assistant Professor, Department of Anatomy, Sri Aurobindo Medical College and Postgraduate Institute, Indore, Madhya Pradesh, India.

2Director/Professor, Department of Anatomy, Sri Aurobindo Medical College and Postgraduate Institute, Indore, Madhya Pradesh, India.

${ }^{3}$ Director/Professor, Department of Anatomy, Sri Aurobindo Medical College and Postgraduate Institute, Indore, Madhya Pradesh, India.

ABSTRACT
BACKGROUND
Low back pain is a major health problem. This is due to inadequate adaptation in lumbar part of vertebral column commensurate
with evolution of bipedal gait. Adequate morphometric information about the bodies of lumbar vertebrae is essential to neuro and
spinal surgeons for various operative procedures of the spine.
So, the present study aims to provide data of anterior and posterior heights of bodies of lumbar vertebrae in Central Indians.

\section{MATERIALS AND METHODS}

Anterior and posterior heights of bodies of lumbar vertebrae were measured digitally in:

1. 10 cadavers (Age: 40 - 60 years) by Vernier Calipers.

2. 120 normal lateral view digital radiographs in the age groups of $21-30$ years (Group I), $31-40$ years (Group II) and 41 - 50 years (Group III) in both the sexes.

\section{RESULTS}

Average heights of all the lumbar vertebrae were recorded in centimetres as follows:

1. Average anterior height was found to be: L1- 2.15, L2- 2.26, L3- 2.38, L4- 2.25 and L5- 2.34 cms in cadavers, while on radiographs it was found to be: L1- 2.79, L2- 2.93, L3- 2.93, L4- 2.92 and L5- $2.93 \mathrm{cms}$.

2. Average posterior height was found to be: L1- 2.37, L2- 2.46, L3- 2.40, L4- 2.30 and L5- 2.12 cms in cadavers, while on radiographs it was found to be: L1- 2.98, L2- 3.06, L3- 3.07, L4- 2.90 and L5- $2.72 \mathrm{cms}$.

\section{CONCLUSION}

Average anterior height < posterior height in all the lumbar vertebrae except at L5 in cadavers and L4-L5 on radiographs. In both cadavers and radiographs, average anterior height increases from L1 to L3, decreases at L4 and increases again at L5. Average posterior height increases upto L2 in cadavers and upto L3 on radiographs. The difference in anterior and posterior heights of bodies of all the lumbar vertebrae in different age groups studied is not significant. It is found that the gender difference in anterior and posterior heights of bodies of various lumbar vertebrae is statistically significant. The present study emphasises the importance of preoperative conventional radiography of each patient in planning a surgical procedure, selecting the appropriate size of the instruments, designing implants and treatment of low back pain. Moreover, these normal figures could also be of forensic importance because of the observed regional variations in lumbar vertebrae.

\section{KEY WORDS}

Lumbar Vertebrae, Morphometry, Low Back Pain.

HOW TO CITE THIS ARTICLE: Agichani S, Joshi SD, Joshi SS. Morphometric study of lumbar vertebrae in central Indian population and its clinical importance. J. Evolution Med. Dent. Sci. 2018;7(38):4129-4133, DOI: 10.14260/jemds/2018/924

\section{BACKGROUND}

Human spine with its distinctive curves is an adaptation to bipedal gait and it becomes a weight bearing column. ${ }^{1}$ The vertebral body is the key element in the load-bearing system of the spine. ${ }^{2}$ This is highlighted by the observation that vertebral centrum size increases craniocaudally. ${ }^{3}$ This is partially responsible for the decreased incidence of fractures

'Financial or Other Competing Interest': None.

Submission 02-08-2018, Peer Review 31-08-2018,

Acceptance 06-09-2018, Published 17-09-2018.

Corresponding Author:

Dr. Sonali Agichani,

\#183, Kalani Nagar,

Airport Road, Indore,

Madhya Pradesh, India.

E-mail:drsonaliagichani@gmail.com

DOI: $10.14260 /$ jemds/2018/924

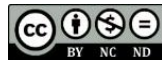

of the lower lumbar spine. In the lumbar region, the significant deviations are a tendency for dorsal heights of the lower lumbar vertebral bodies to decrease below L2.4 Lumbar vertebra has kidney shaped body, wider transversely than the anteroposterior depth and height. The fifth lumbar vertebra is a transitional vertebra and differs from the rest of the lumbar vertebrae, in that it has a wedge shaped body 5 which is the largest and is markedly deeper anteriorly. ${ }^{6}$

Dimensions of lumbar vertebrae hold great relevance in clinical diagnosis of lower backache. Population specific variations are common in many body dimensions of lumbar vertebrae. ${ }^{7}$ Knowledge of lumbar morphometry is vital not only for the understanding of biomechanics of lumbar spine, but also for various interventions aimed at its stabilisation and correction of deformities, ${ }^{8}$ which is essential for the spinal implants design, lumbar decompression surgery and workspace definition for robot-assisted surgery. ${ }^{9}$ 
Morphometric studies published by many authors have established that the vertebrae undergo continuous growth and remodelling throughout life, presumably in response to the changing needs of the body. ${ }^{10}$ It is also important to distinguish differences in morphometry of vertebrae in males and females and to understand changes in the elderly persons, as incorrect placement of instruments and devices may have serious complications. ${ }^{8}$ The morphological changes of the vertebrae associated with normal aging are still subject of debate, whereas this knowledge is important in detecting vertebral fractures and degenerative shape changes. ${ }^{9}$ Sex can be estimated from first lumbar vertebra with reasonable accuracy in medico-legal cases when skeletal remains are incomplete. ${ }^{11}$

\section{MATERIALS AND METHODS}

This is a retrospective descriptive study. The present work has been carried out in the Department of Anatomy and Radiodiagnosis, SAMC and PGI, Indore.

\section{The Material Comprised of 2 Groups}

1. Ten Cadavers (40 - 60 yrs.) available in the Department of Anatomy.

2. 120 Lateral view digital x-rays of normal adults (60 males and 60 females divided into 3 age groups).

\section{Objective}

The present study is to measure morphometry of lumbar vertebrae in Central Indians.

\section{A. Cadaveric Study}

Ten adult cadavers fixed in $10 \%$ formalin in the Department of Anatomy, Sri Aurobindo Medical College and PG Institute, Indore, were used for the present study. The cadavers were in the age group of 40 - 60 years. Lumbar region along with lumbosacral junction was dissected. After removing all the viscera, the muscles of posterior abdominal wall were exposed. Psoas major was dissected out carefully from intervertebral discs and vertebral bodies. The abdominal aorta and inferior vena cava were also removed from the front of the vertebral column, so as to expose the front of vertebrae and the intervertebral discs. The lumbosacral part of the vertebral column was separated in one piece by using a saw. These specimens contained the vertebral bodies and intervertebral discs from the upper border of L1 to the lower border of L5 along with sacrum and the 2 hip bones. Median section was cut by an electric saw. The anterior and posterior heights of bodies of lumbar vertebrae were measured using Digital Vernier Caliper (Fig. 1). The average was calculated and tabulated (Table 1)

\section{B. Radiological Study}

120 (lateral view) digital radiographs of normal healthy adults were obtained from the Department of Radiodiagnosis of Sri Aurobindo Medical College and PG Institute, Indore. Ethical clearance was taken from the Institutional Ethical Committee.

These Adults were in the Age Group of 21 to 50 Years of both Sexes. Observations were recorded by Forming SubGroups-

1. Age Group I: 21 - 30 years.

2. Age Group II: $31-40$ years.
3. Age Group III: $41-50$ years.

Each age group comprised of 40 cases, of which 20 were males and 20 were females.

\section{In all Lateral Radiographs (Digitalised)}

Anterior and posterior heights of vertebral bodies were directly measured digitally (Fig. 2), and the average and standard deviation were calculated. The values so obtained were put to statistical tests and tabulated (Table 2 and 3 ).

\section{Statistical Analysis}

The obtained data was tabulated and analysed for descriptive statistics. The average and standard deviation of the abovementioned parameters were calculated and recorded. OneWay ANOVA was used. The association of vertebral body dimensions with age was calculated using Analysis of Variance (ANOVA). A significance level of $\mathrm{P}<0.05$ was used. Student's t-test was used to analyse the significance of gender differences. $\mathrm{P}<0.05$ (Significant).

\section{RESULTS}

\section{In Cadavers}

The anterior and posterior heights of bodies of lumbar vertebrae were measured by Digital Vernier Caliper. Observations were recorded, and their average was tabulated (Table 1). The average anterior height in centimetres were: L1- 2.15, L2- 2.26, L3- 2.38, L4- 2.25, L5- 2.34 and the average posterior heights in centimetres were: L1- 2.37, L2- 2.46, L32.40, L4- 2.30, L5- 2.12. From these readings, it is concluded that in cadavers-

- Average anterior height < posterior height except at L5.

- Average anterior height increases from L1 to L3, decreases at L4 and increases again at L5.

- $\quad$ Average posterior height increases upto L2.

\section{On Digital X-Rays}

The anterior and posterior heights of lumbar vertebral bodies were measured digitally as seen in Fig. 2. Average and standard deviation was calculated. In total 120 radiographs, (Table 2) the average anterior height in centimetres were L12.79, L2 and L3- 2.93, L4- 2.92, L5- 2.93 and the average posterior height in centimetres were L1- 2.98, L2- 3.06, L33.07, L4- 2.90 and L5- 2.72.

\section{From these Readings, it is concluded that-}

- $\quad$ Average anterior height < posterior height except at L4 and L5.

- Average anterior height increases from L1 to L3, decreases at L4 and increases again at L5.

- Average posterior height increases upto L3.

The observations were divided into 3 subgroups according to age (Table 2). Each age group was further divided gender wise (Table 3). Average and standard deviation was calculated.

\section{From these Readings, it is concluded that-}

1. Average anterior height < Posterior height upto L3 in all the age groups and in both sexes except in Age Group III in females where average anterior height $<$ posterior height was upto L4.

2. Average anterior height in- 


\section{Group I}

Males- It increases from L1 to L5.

Females- It increases upto L2, then decreases upto L4 and increases again at L5.

\section{In Group II and III}

Males- It increases upto L3, decreases at L4, increases at L5. Females- It increases upto L2 and then decreases upto L5.

\section{Average Posterior Height in-}

Group I

- Males- It increases upto L3.

- $\quad$ Females- It increases upto L2.

Group II: In both the sexes, it increases upto L3.

Group III: It increases upto L2 in both the sexes.

\section{Statistical Inferences}

$P$ value $<0.05$ (significant) analysed by ANOVA (Table 2).

Analysis by ANOVA revealed non-significant association between anterior and posterior heights of bodies of all the lumbar vertebrae in various age groups.

P-value $<0.05$ (Significant) analysed by Independent $\mathrm{t}$ test (Table 3).

It is revealed that there is significant association between gender and anterior heights of bodies of $4^{\text {th }}(P=0.003)$ and $5^{\text {th }}$ $(\mathrm{P}=0.003)$ lumbar vertebrae in Age Group-I. In the same age group, there is significant association between gender and posterior heights of bodies of all the lumbar vertebrae ( $P$ value for $\mathrm{L} 1=0.033, \mathrm{~L} 2$ and $\mathrm{L} 3=0.002, \mathrm{~L} 4$ and $\mathrm{L} 5=0.000$ ).

Similarly, significant association was seen between gender and anterior height of body of $5^{\text {th }}(\mathrm{P}=0.010)$ lumbar vertebra in Group-III ( 41 - 50 yrs.). In the same age group, there was significant association between gender and posterior height of body of $1^{\text {st }}(\mathrm{P}=0.033)$ lumbar vertebra.

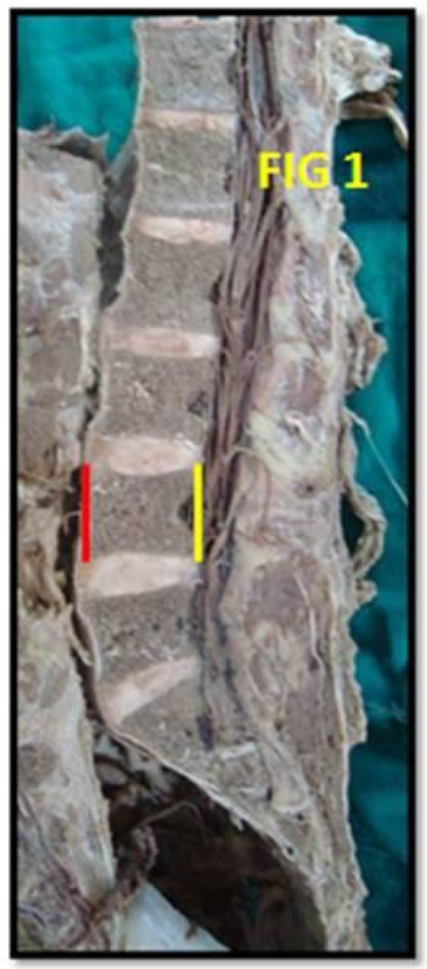

Figure 1. Median Section of Cadaver showing Anterior (Red) and Posterior (Yellow) Heights measured on Lumbar Vertebral Body

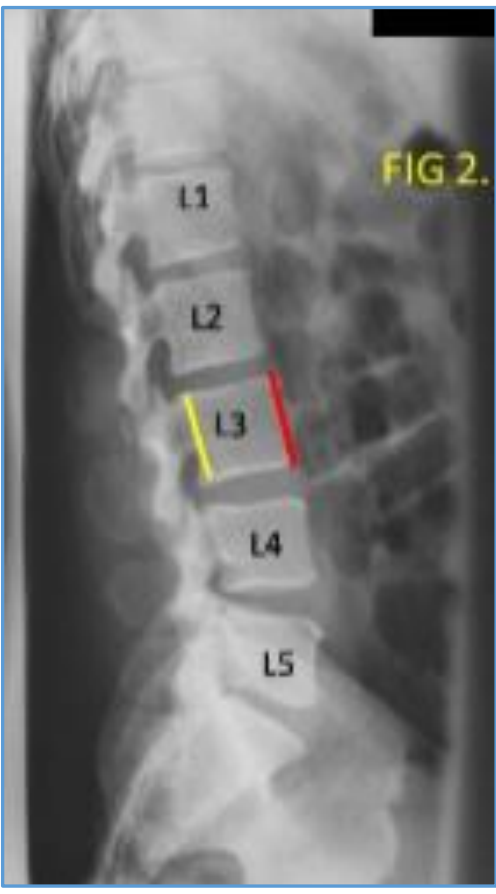

Figure 2. Lateral View Digital Radiograph of Lumbar Spine showing Anterior (Red) and Posterior (Yellow) Heights measured on Lumbar Vertebral Body

\begin{tabular}{|l|l|l|}
\hline \multicolumn{3}{|c|}{$\begin{array}{c}\text { Table- } 1: \\
\text { Average anterior and posterior heights of lumbar vertebral bodies in cadavers }\end{array}$} \\
\hline V.no & Anterior ht(cms) & Posterior ht(cms) \\
\hline L1 & 2.1551 & 2.3799 \\
\hline L2 & 2.2685 & 2.4665 \\
\hline L3 & 2.3809 & 2.4018 \\
\hline L4 & 2.2555 & 2.3005 \\
\hline L5 & 2.3488 & 2.1288 \\
\hline
\end{tabular}

Table 1. Average Anterior and Posterior Heights of Bodies of Lumbar Vertebrae in Median Sections of Cadavers

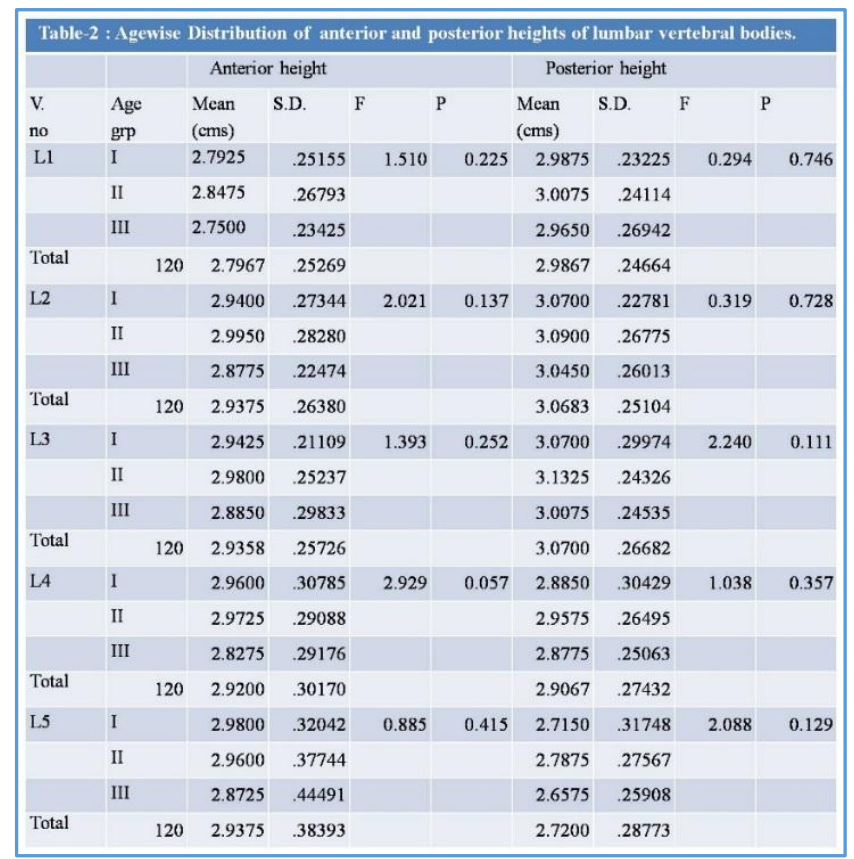

Table 2. V. No- Number of Vertebra; L-Lumbar; 40 Subjects in each age group; Group I: 21-30 Years, Group II: 31-40 Years, Group III: 41-50 Years 


\begin{tabular}{|c|c|c|c|c|c|c|c|c|c|c|}
\hline \multirow{3}{*}{$\begin{array}{l}\text { Age } \\
\text { grp } \\
\text { I }\end{array}$} & \multirow[b]{2}{*}{ Vno } & \multirow[b]{2}{*}{ Sex } & \multirow[b]{2}{*}{$\begin{array}{l}\text { Mcan } \\
(\mathrm{cm})\end{array}$} & \multicolumn{3}{|c|}{ Anterior height } & \multicolumn{4}{|c|}{ Posterior height } \\
\hline & & & & S.D & $\begin{array}{l}\text { Itest } \\
\text { value }\end{array}$ & P value & $\begin{array}{l}\text { Mcan } \\
\text { (cm) }\end{array}$ & s.D. & $\begin{array}{l}\text { t test } \\
\text { value }\end{array}$ & Pvaluc \\
\hline & L1 & Males & 2.8250 & 27314 & 0.814 & 0.421 & 3.0650 & .23681 & 22.13 & 0.033 \\
\hline & & Females & 2.7600 & .23033 & & & 2.9100 & .20494 & & \\
\hline & 1.2 & Males & 2.9900 & 26735 & 1.162 & 0.253 & 3.1750 & .19433 & 3.254 & 0.002 \\
\hline & & Females & 2.8900 & .27701 & & & 2.9650 & .21343 & & \\
\hline & I.3 & Males & 3.0050 & .16694 & 1.938 & 0.060 & 3.2100 & 29540 & 3310 & 0.002 \\
\hline & & Females & 2.8800 & 23530 & & & 2.9300 & .23642 & & \\
\hline & $\mathrm{L} 4$ & Males & 3.1000 & 25547 & 3.199 & 0.003 & 3.0500 & .27048 & 4.051 & 0.000 \\
\hline & & Females & 2.8200 & 29665 & & & 2.7200 & .24409 & & \\
\hline & L.5 & Males & 3.1250 & .28814 & 3.179 & 0.003 & 2.8950 & .21879 & 4.323 & 0.000 \\
\hline & & Females & 2.8350 & 28887 & & & 2.5350 & 30136 & & \\
\hline \multirow[t]{10}{*}{ II } & LI & Males & 2.8950 & 27999 & 1.125 & 0.268 & 3.0350 & .26808 & 0.717 & 0.478 \\
\hline & & Females & 2.8000 & .25340 & & & 2.9800 & .21423 & & \\
\hline & 1.2 & Males & 3.0400 & 27028 & 1.007 & 0.321 & 3.1250 & .28261 & 0.823 & 0.415 \\
\hline & & Females & 2.9500 & 29469 & & & 3.0550 & .25438 & & \\
\hline & L3 & Males & 3.0450 & 27237 & 1.666 & 0.104 & 3.1750 & .23814 & 1.108 & 0.275 \\
\hline & & Females & 2.9150 & 21831 & & & 3.0900 & .24688 & & \\
\hline & LA & Males & 3.0300 & 28488 & 1.260 & 0.215 & 3.0150 & .28521 & 1.389 & 0.173 \\
\hline & & Females & 2.9150 & 29249 & & & 2.9000 & .23620 & & \\
\hline & L.5 & Males & 3.0700 & 33419 & 1.904 & 0.064 & 2.8250 & .29357 & 0.857 & 0.397 \\
\hline & & Females & 2.8500 & 39403 & & & 2.7500 & .25854 & & \\
\hline \multirow{10}{*}{ III } & L1 & Males & 2.7900 & 21981 & 1.082 & 0.286 & 3.0550 & .25021 & 2216 & 0.033 \\
\hline & & Females & 2.7100 & .24688 & & & 2.8750 & .26333 & & \\
\hline & L2 & Males & 2.9150 & 19270 & 1.057 & 0.297 & 3.1000 & .25955 & 1.351 & 0.185 \\
\hline & & Females & 2.8400 & 25215 & & & 2.9900 & .25526 & & \\
\hline & L3 & Males & 2.9550 & 26848 & 1.508 & 0.140 & 3.0550 & .24382 & 1233 & 0.225 \\
\hline & & Females & 2.8150 & 31669 & & & 2.9600 & .24366 & & \\
\hline & 14 & Males & 29100 & 26137 & 1.842 & 0.073 & 2.9050 & .20641 & 0.689 & 0.495 \\
\hline & & Females & 2.7450 & 30345 & & & 2.8500 & .29110 & & \\
\hline & I.5 & Males & 3.0500 & .48395 & 2.723 & 0.010 & 2.7150 & .28149 & 1.422 & 0.163 \\
\hline & & Females & 2.6950 & .32521 & & & 2.6000 & 22711 & & \\
\hline
\end{tabular}

Table 3. V. No-Number of Vertebra; L-Lumbar; 20 Males and 20 Females, in each age group. Group I: 21-30 Years, Group II: 31-40 Years, Group III: 41-50 Years

\section{DISCUSSION}

According to El Sayed et al (2014), ${ }^{12}$ low back pain is one of the most frequently observed symptoms in the human musculoskeletal system. The results of morphometry of lumbar vertebral bodies offer a guidance to clinicians for the evaluation and management of subjects complaining of low back pain in order to propose specific preventive or rehabilitation protocols.

Mavrych et al (2014) ${ }^{9}$ in a study on lumbar vertebrae of 212 cadavers ( 0 - 90 yrs.) have concluded that measurements of vertebral body heights indicated a most rapid growth of anterior height of L3, one of the factors that contributes to the lumbar curve formation. Their results showed a slight decrease in vertebral body heights in senior persons due to osteopenia.

Mavrych et al (2014), ${ }^{9}$ citing the work of Gilad et al (1985) and Diacinti et al $(2010,2011)$ stated that they are of the same opinion; while Castillo et al (1998) and Masharawi et al (2008) expressed that decrease in human height with aging results from a decrease in the thickness of the intervertebral discs only. We have also found the same results as that of Mavrych et al (2014) ${ }^{9}$ with advancing age in Group III (41 - 50 yrs.). Their results showed a statistically significant correlation between all vertebral body dimensions and age for both men and women. This is in contrast with earlier studies by Masharawi et al (2008), who did not find such a correlation. The contrasting findings were possibly due to their larger sample size and the age groups used in their study (age range 0 - 90 years vs. 20 - 80 years). In our study, Analysis by ANOVA revealed non-significant association between anterior and posterior heights of bodies of all the lumbar vertebrae in various age groups.

According to Mavrych et al (2014), ${ }^{9}$ there was no sexual dimorphism in measurements of lumbar vertebral bodies $(\mathrm{P}>0.05)$. As cited by them, Gilsanz et al (1994) and GocmenMas et al (2010) opine the same. But in the present study, in Group-I (21 - 30 yrs.), it is revealed that there is significant association between gender and anterior heights of bodies of $4^{\text {th }}(\mathrm{P}=0.003)$ and $5^{\text {th }}(\mathrm{P}=0.003)$ lumbar vertebrae. In the same age group, there is significant association between gender and posterior heights of bodies of all the lumbar vertebrae $(\mathrm{P}$ value for $\mathrm{L} 1=0.033, \mathrm{~L} 2$ and $\mathrm{L} 3=0.002, \mathrm{~L} 4$ and L5= 0.000). Similarly, in Group-III (41 - 50 yrs.), significant association was seen between gender and anterior height of body of $5^{\text {th }}(\mathrm{P}=0.010)$ lumbar vertebra. In the same age group, significant association was found between gender and posterior height of body of $1^{\text {st }}(\mathrm{P}=0.033)$ lumbar vertebra.

Regarding the anterior heights of bodies of lumbar vertebrae, Gocmen-Mas et al (2010) ${ }^{10}$ on Anatolians recorded (on MRI), smaller values than the present values in females, while El Sayed et al (2014)12 in Lebanese adult females recorded (on plain radiographs) greater values than the present ones in females. However, their results showed a gradual cephalocaudal increase, but we found such increase only upto L2 in females. Posterior heights of lumbar vertebral bodies recorded by El Sayed et al (2014) ${ }^{12}$ are also greater than the present ones, but these values showed craniocaudal increase only upto L2 as found in our study.

In a study on 24 subjects by Abuzayed et al (2010), 13 the anterior height of the vertebral body was smallest at the L4 level $(26.2 \mathrm{~mm})$ and largest at the L5 level $(28.5 \mathrm{~mm})$. The anterior height showed an increase from the L1 to L5 level, except for a decrease at the $\mathrm{L} 4$ level. In our radiographic study, smallest anterior height is at L1 (27.9 $\mathrm{mm})$ and largest is at L2, L3 and L5 (29.3 mm). Our study also shows a decrease at L4. In their study, the posterior height of the vertebral body was smallest at the L5 level $(22.9 \mathrm{~mm})$ and largest at the $\mathrm{L} 2$ and $\mathrm{L} 3$ levels $(27.3 \mathrm{~mm})$. It showed a gradual increase from the L1 to the L2 and L3 levels, and then decreased towards the L5 level. We also got similar results with different values, the smallest posterior height at L5 being $27.2 \mathrm{~mm}$ and largest at L3 being $30.7 \mathrm{~mm}$. In their study, the anterior height of the vertebral bodies was smaller than the posterior height at the L1 and L2 levels, same as the posterior height at the L3 and L4 levels, and larger than the posterior height at the L5 level. But we found anterior heights smaller than the posterior upto L3 and the reverse at L4 and L5. According to Hegazy et al (2014), ${ }^{14}$ the compressive loads occur more on the posterior concave aspects, particularly of lower lumbar segments resulting in decrease in the posterior heights. Gocmen-Mas et al (2010),10 Hegazy et al (2014) ${ }^{14}$ and Abuzayed et al (2010),13 the values found in their study are smaller than those found in our study. These normal figures could also be of forensic importance because of the observed racial, ethnic and regional variations. ${ }^{12}$

Referring to the work of Vialle et al (2005), Hegazy et al (2014) ${ }^{14}$ have said that lumbar lordosis is formed by wedging of the lumbar vertebral bodies and of the intervertebral discs. Hegazy et al (2014) ${ }^{14}$ have cited the work of Lengsfeld et al (2000) who have stated that a lordotic posture of the lumbar 
spine should be maintained during sitting, but prolonged sitting and increased lumbar lordosis is generally accepted as a high-risk factor in low back pain. The increase in lordosis may be attributed to an alteration in the intervertebral discs and a loss in the posterior vertebral body height of lumbar spine.

Hegazy et al (2014),14 in their retrospective study on normal MRI's have found that the Anterior Height (AH) of lumbar vertebral bodies in both sexes increased in a craniocaudal direction. But in our study same results are found in males, while in females it increased upto L2 only. In their study regarding the Posterior Height $(\mathrm{PH})$, there was an increase in its mean in males from L1 (m: $26.30 \mathrm{~mm})$ to L2 (m: $27.13 \mathrm{~mm}$ ) followed by a slight and gradual decrease to L5 ( $\mathrm{m}: 24.09 \mathrm{~mm})$. The PH in females showed the same trend of the male $\mathrm{PH}$, but the change in the values occurred at L3 instead of L2. In our study, PH increased upto L3 in males and upto L2 in females. In their study, these dimensions of male vertebrae were greater than those of females with variable values. We have also got the same results. Alam et al (2014) ${ }^{8}$ have also concluded that all the dimensions of lumbar vertebrae were greater in males than females, in that the anterior body height was found to be significantly greater in males in L5 vertebra $(p<0.05)$ and the posterior heights of L1, L2 and L3 were significantly greater in males $(p<0.05) .^{8}$

Blake et al (1997) have stated that vertebral fractures are usually diagnosed by visual interpretation of lateral radiographs of the lumbar and thoracic spine. Vertebral morphometry based on measurements of the heights of the vertebral bodies is a useful adjunct to the visual reading of radiographs. Mavrych et al (2014) ${ }^{9}$ have stated that information regarding the precise dimensions of the lumbar vertebral bodies is essential for spinal surgery and instrumentation. Gocmen-Mas et al (2010) ${ }^{10}$ has referred to the work of Chou et al (2008) and said that measurements of size and volumetric definition for bodies of lumbar vertebrae are important for preventing complications after anterior approach in spinal surgeries.

\section{CONCLUSION}

Our study suggests similarity in trend of lumbar vertebral body heights from both direct and imaging measurements. We have found non-significant association between anterior and posterior heights of bodies of all the lumbar vertebrae and in various age groups. In Age Group-I, significant association was found between gender and posterior heights of all, and anterior heights of $4^{\text {th }}$ and $5^{\text {th }}$ lumbar vertebral bodies. In Age Group-III, significant association was found between gender and posterior height of $1^{\text {st }}$ and anterior height of $5^{\text {th }}$ lumbar vertebral bodies.

The present study thus emphasises the importance of preoperative conventional radiography of each patient in planning a surgical procedure, selecting the appropriate size of the instruments, designing implants and treatment of low back pain. Moreover, these normal figures could also be of forensic importance because of the observed regional variations.

\section{ACKNOWLEDGEMENT}

We would like to thank Dr. Harshal Gupta, Associate Professor in PSM department for helping in statistical work.

\section{REFERENCES}

[1] Evolution doesn't explain erect human vertebral column.

http://evolutionwiki.org/wiki/Evolution_doesn't_expl ain_erect_human_vertebral_column.

[2] Leone A, Guglielmi G, Cassar-Pullicino VN, et al. Lumbar intervertebral instability: a review. Radiology 2007;245(1):62-77.

[3] Briggs AM, Greig AM, Wark JD, et al. A review of anatomical and mechanical factors affecting vertebral body integrity. Int J Med Sci 2004;1(3):170-80.

[4] Kowalski RJ, Ferrara LA, Benzel EC. Biomechanics of the Spine. Neurosurg Q 2005;15(1):42-59.

[5] Levangie PK, Norkin CC. Joint structure and function a comprehensive analysis. $4^{\text {th }}$ edn. Jaypee Brothers 2006: p. 144-76, 490.

[6] Standring S, Healy JC, Johnson D, et al. Grays Anatomy: the anatomical basis of clinical practice. $40^{\text {th }}$ edn London: Churchill Livingstone 2008: p. 535, 714-44.

[7] Azu 00, Komolafe OA, Ofusori DA, et al. Morphometric study of lumbar vertebrae in adult South African subjects. Int J Morphol 2016;34(4):1345-51.

[8] Alam MM, Waqas M, Shallwani $H$, et al. Lumbar morphometry: a study of lumbar vertebrae from Pakistani population using computed tomography scans. Asian Spine J 2014;8(4):421-6.

[9] Mavrych V, Bolgova O, Ganguly P, et al. Age-related changes of lumbar vertebral body morphometry. Austin J Anat 2014;1(3):1014.

[10] Gocmen-Mas N, Karabekir H, Ertekin T, et al. Evaluation of lumbar vertebral body and disc: a stereological morphometric study. Int J Morphol 2010;28(3):841-7.

[11] Ramadan N, Abd El-Salam MH, Hanon AF, et al. Identification of sex and age for Egyptians using computed tomography of the first lumbar vertebra. Egyptian Journal of Forensic Sciences 2017;7:22.

[12] Atta-Alla el SS, Saab IM, EI Shishtawy M, et al. Morphometric study of the lumbosacral spine and some of its related angles in Lebanese adult females. Ital J Anat Embryol 2014;119(2):92-105.

[13] Abuzayed B, Tutunculer B, Kucukyuruk B, et al. Anatomic basis of anterior and posterior instrumentation of the spine: morphometric study. Surg Radiol Anat 2010;32(1):75-85.

[14] Hegazy AA, Hegazy RA. Midsagittal anatomy of lumbar lordosis in adult Egyptians: MRI study. Article ID 370852, Anatomy Research International 2014;2014: p. 12. http://dx.doi.org/10.1155/2014/370852 